\title{
Induction heating based on permanent magnets with magnetic field concentrators
}

\author{
Aliferov A.I. \\ Department of automated technological installations \\ Novosibirsk State Technical University \\ Novosibirsk, Russia \\ alif@ngs.ru \\ Vlasov D.S. \\ Department of automated technological installations \\ Novosibirsk State Technical University \\ Novosibirsk, Russia \\ d.vlasov@corp.nstu.ru
}

\author{
Promzelev V.A. \\ Department of automated technological installations \\ Novosibirsk State Technical University \\ Novosibirsk, Russia \\ promzelev@mail.ru \\ Morev A.E. \\ Department of automated technological installations \\ Novosibirsk State Technical University \\ Novosibirsk, Russia \\ glhficcup@yandex.ru
}

\author{
Bikeev R.A. \\ Department of automated technological installations \\ Novosibirsk State Technical University \\ Novosibirsk, Russia \\ bikeev@ngs.ru
}

\begin{abstract}
To study the effect of various types of magnetic field concentrators on the energy and thermal characteristics of the induction heating system of noncylindrical billets in the magnetic field of rotating permanent magnets, a numerical model was developed. The model allows solving the conjugate electromagnetic and thermal problem. Using the model, the authors were able to calculate the integral active power released in the heated billet, the mechanical moment that the magnetic system experiences from the current induced in the billet and the distribution of the temperature field in the "inductor-heated billet" system. In this paper, the authors consider the results of numerical studies of heating aluminum billets with a rectangular cross-section and the influence of several types of magnetic field concentrators on the electromagnetic and thermal processes in this system.
\end{abstract}

Keywords- Induction heating, permanent magnet, temperature field, magnetic field, alternating magnetic field, active power.

\section{INTRODUCTION}

Special attention is given to heating of billets from nonmagnetic metals in an alternating magnetic field created by rotating systems with permanent magnets, since in the industry such preforms are heated in induction heating installations in a longitudinal alternating magnetic field having an electric efficiency of $\eta \leq 0.5$. A feature of heating such billets in a transverse rotating magnetic field of permanent magnets is its potential to achieve an electrical efficiency of 0.75-0.85 [1-2]. A number of publications describe the results of the study of the energy, electrical, mechanical parameters and temperature conditions of heating cylindrical nonmagnetic billets in installations that realize this type of heating [2-7].

The results obtained for cylindrical billets can not be applied to billets of another cross-section: rectangular, rhomboid, elliptical, etc. To fill this gap, studies were performed and the results of calculations of the heating regimes for aluminum billets of rectangular cross section are presented.

\section{PROBLEM STATEMENT}

Figure 1 is a schematic diagram of an induction heating device for blanks of a rectangular cross-section in a rotating field of permanent magnets.

The heating of aluminum products is performed up to a temperature of $550{ }^{\circ} \mathrm{C}$. The technological gap between the edge of a rectangular billet and magnets was assumed to be 10 $\mathrm{mm}$. Magnet height is $\mathrm{h}=15 \mathrm{~mm}$, residual induction is $1 \mathrm{~T}$, coercive force is $1050 \mathrm{kA} / \mathrm{A}$ (direction of magnetization radial). The process of convective heat transfer of the surface of a rotating billet with the surrounding medium was carried out under a boundary condition of the third kind.

Created in the software complex ANSYS, the numerical model is designed to calculate the interrelated electromagnetic and thermal processes in the heated billet, taking into account the changing electrophysical properties of the material of the heated billet and nonlinear heat transfer on its surface. 


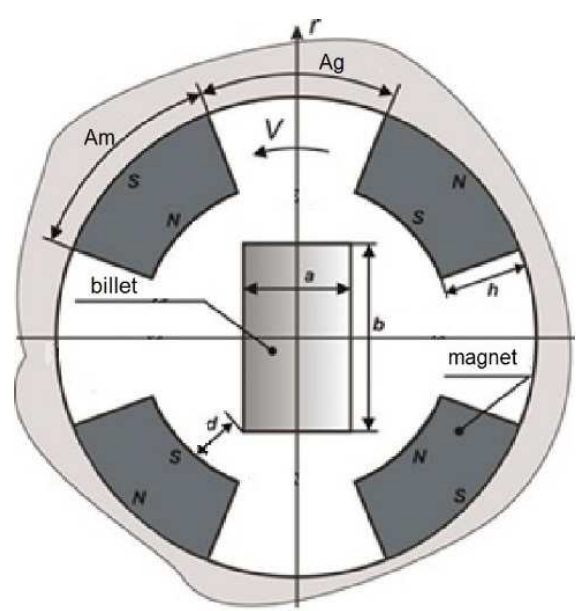

Fig. 1. Diagram of the induction heating of a rectangular cross-section billet in a rotating field of permanent magnets: $h$ is the height of the magnets; $S, N$ south and north poles of the magnet, respectively; Am is the angular size of the magnet; $\mathrm{Ag}$ is the angular size of the gap between the magnets in the magnetic system; a, b - width and height of the heated billet; $d$ is the gap between the heated billet and the surface of the magnets; V - direction of rotation of the magnetic system around the heated billet.

Through the developed model, it is possible to study the electromagnetic parameters, energy characteristics and temperature field over the cross section of the heated billet, which are functionally dependent on the speed of rotation of the system of magnets relative to the billet, the number of pairs of poles of the magnetic system, the physical properties of the heated billet and the system of permanent magnets.

\section{RESEARCH FINDINGS}

Figures 2 - 3 show the distribution of the temperature field in the billet from its geometric dimensions and the regime parameters of heating. These dependencies show that in the rectangular billet, irrespective of the frequency of the magnetic field, the corners of the preform are heated more intensively, and then, due to the thermal conductivity from the energy release zone, the rest of the body. With an increase in the speed of rotation and the number of pairs of poles of the magnetic system, the heating rate and the maximum temperature drop in the billet are significantly increased, exceeding the temperature difference admissible by the through-heating technology. Therefore, the development of devices that equalize the temperature difference is required. Such devices are selected magnetic field concentrators.

It can be seen from Fig. 4 that with increasing technological gap between the billet and the surface of the magnets, the rate of heating of the billet decreases. This behavior of the heating rate is associated with a decreasing specific active power released in the billet.

Scientific studies carried out with the financial support of Novosibirsk State Technical University

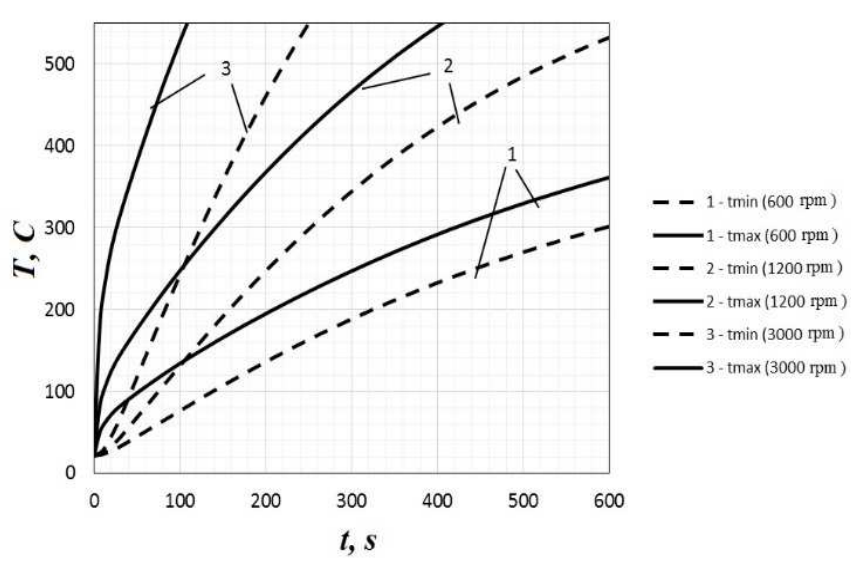

Fig. 2. Dependence of the distribution of the temperature field in a rectangular billet with a cross-section of $180 \times 90 \mathrm{~mm}$ (clearance $\mathrm{d}=10 \mathrm{~mm}$ ) of the rotation speed of the magnetic system of the installation with 3 pairs of poles.

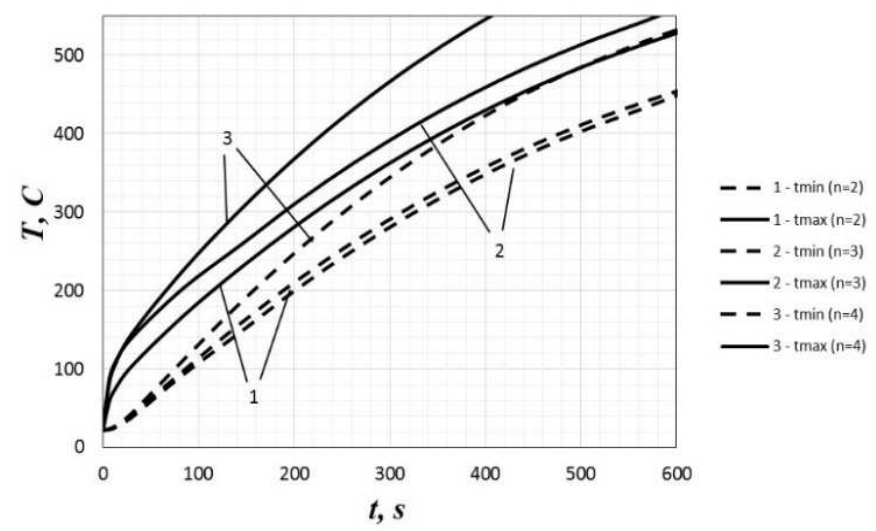

Fig. 3. Dependence of the distribution of the temperature field in a rectangular blank with a cross-section of $180 \times 90 \mathrm{~mm}$ on the number of pole pairs of the magnetic system of the installation at a rotation speed of $1200 \mathrm{rpm}$.

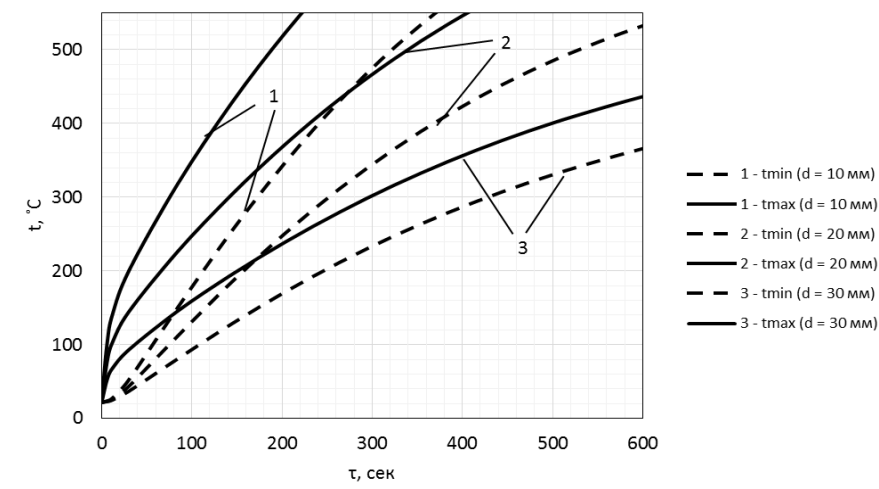

Fig. 4. Dependence of the distribution of the temperature field in a rectangular billet at a frequency of rotation of the magnetic system of $1200 \mathrm{rpm}$ of the installation with 3 pairs of poles from the technological gap between the billet and the system of magnets.

\section{A. Application of magnetic field concentrators.}

The alignment of the temperature field in rectangular billets can be achieved by using magnetic field concentrators that, when the system of magnets rotates around the module including the heated billet and concentrators, creates a pulsating magnetic field in the workpiece. In the problem 
under consideration, the concentrators of the magnetic field occupy the entire space outlined by their external contour.

Table 1 shows the initial data for the calculation.

TABLE I. INITIAL DATA OF THE CALCULATION SYSTEM

\begin{tabular}{|c|c|c|}
\hline Name & Unit & Value \\
\hline $\begin{array}{c}\text { The speed of rotation of } \\
\text { the magnetic system. }\end{array}$ & $\mathrm{r} / \mathrm{sec}$ & 20 \\
\hline Number of pole pairs & pieces & 3 \\
\hline $\begin{array}{c}\text { The length of the } \\
\text { rectangular billet }\end{array}$ & $\mathrm{m}$ & 0,140 \\
\hline $\begin{array}{c}\text { Width of the rectangular } \\
\text { billet }\end{array}$ & $\mathrm{m}$ & 0,100 \\
\hline Magnet width & $\mathrm{m}$ & 0,112 \\
\hline Magnet height & $\mathrm{T}$ & 1,08269 \\
\hline $\begin{array}{c}\text { Residual induction of } \\
\text { magnets }\end{array}$ & $\mathrm{A} / \mathrm{m}$ & 1050000 \\
\hline Coercive force of magnets & & 0 \\
\hline $\begin{array}{c}\text { Angle of coercive force } \\
\text { vector of magnets }\end{array}$ & & 130 \\
\hline $\begin{array}{c}\text { Magnetic permeability of } \\
\text { magnetic field } \\
\text { concentrators }\end{array}$ & & \\
\hline
\end{tabular}

Figure 5 shows two arrangements for concentrating the schemes of the magnetic field.

Figure 6 shows the time dependences of the integrated power extracted in a rectangular billet in the system "heated billet - rotating magnets" in the absence and presence of magnetic field concentrators.

The use of magnetic field concentrators leads to a decrease in the active power released in the billet. Moreover, such a reduction is more significant when concentrators are installed along the side surfaces of the billet, and not at its corners.

The temperature distribution shown in Figure 7 illustrates the significant influence of magnetic field concentrators on the temperature distribution over the surface of a rectangular billet. With concentrators located at the lateral surface of the billet, a more uniform temperature field over its surface is obtained.

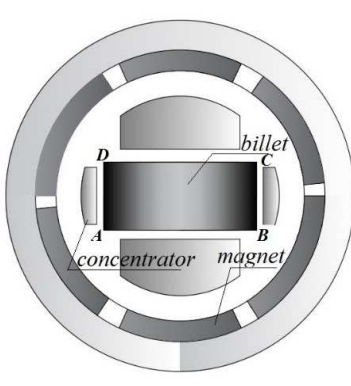

a)

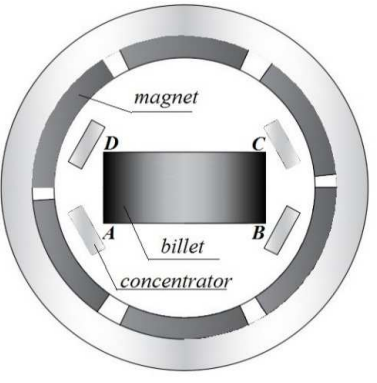

b)
Fig. 5. Scheme of induction heating installation: a) with magnetic field concentrators at the side surfaces of the billet, b) with magnetic field concentrators located at the corners $[8,10]$.

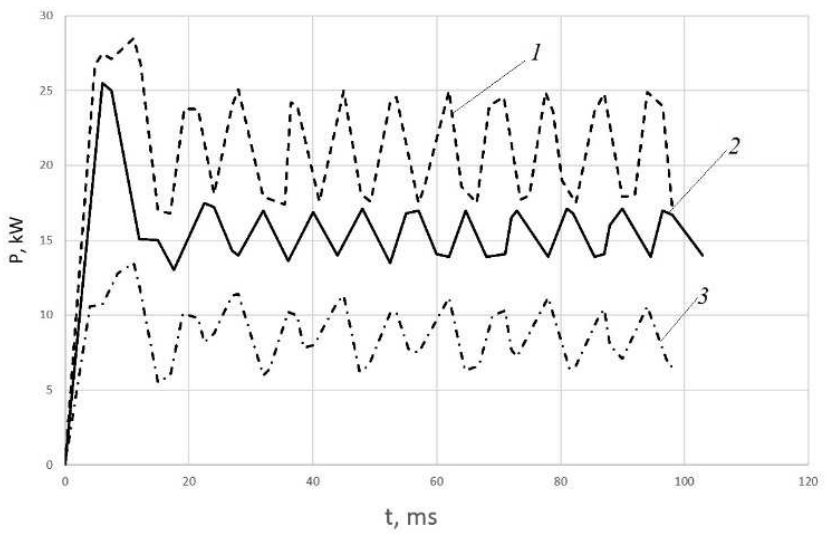

Fig. 6. Time dependence of the integral active power in the billet: 1- without magnetic field concentrators, 2 - with magnetic field concentrators at the corners of the billet, 3 - with concentrators at the side surfaces.

Figure 7 shows the temperature distribution along the perimeter of the rectangular billet $\mathrm{ABCD}$, shown in Fig. 4. The curves are given for different time points and different active powers.

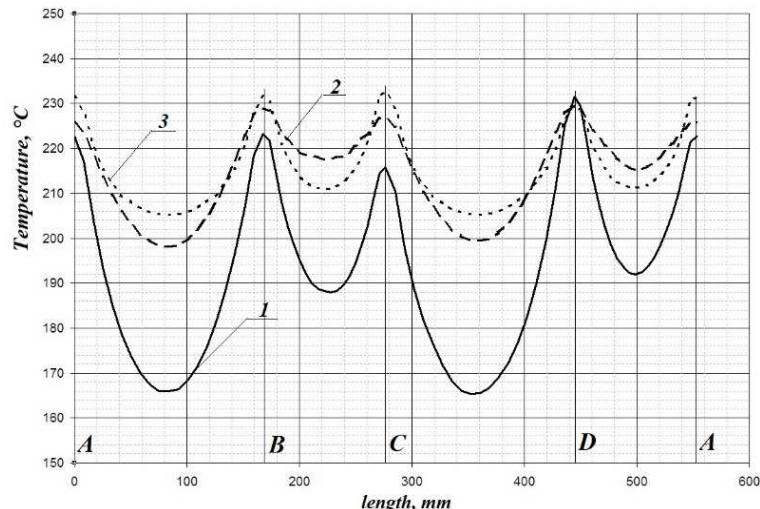

Fig. 7. Temperature distribution along the perimeter of the rectangular billet: 1 - without magnetic field concentrators, 2 - with magnetic field concentrators at the corners of the billet, 3 - with magnetic field concentrators at the side surfaces.

Figure 8 shows the dependence of the integral mechanical moment of resistance of a rectangular billet for different versions of an induction heating system. The integral mechanical moment experienced by a rectangular billet decreases with the use of concentrators.

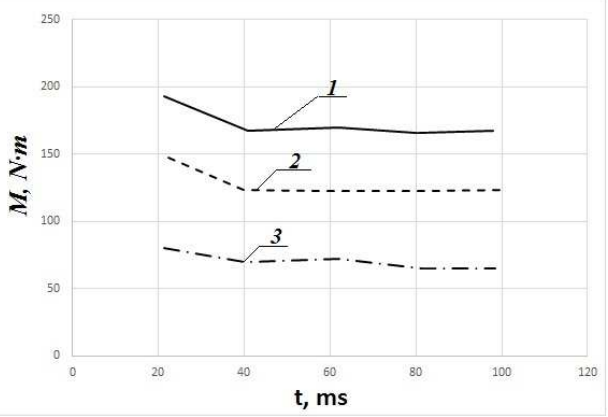

Figure 8. Dependence of the integral moment of resistance of a rectangular billet: 1 - without magnetic field concentrators, 2 - with magnetic field concentrators located at the corners of the billet, 3 - with concentrators located at the side surfaces of the billet. 
The third variant of constructive execution of concentrators in the form of a distributed magnetic circuit is shown in Fig. 9.

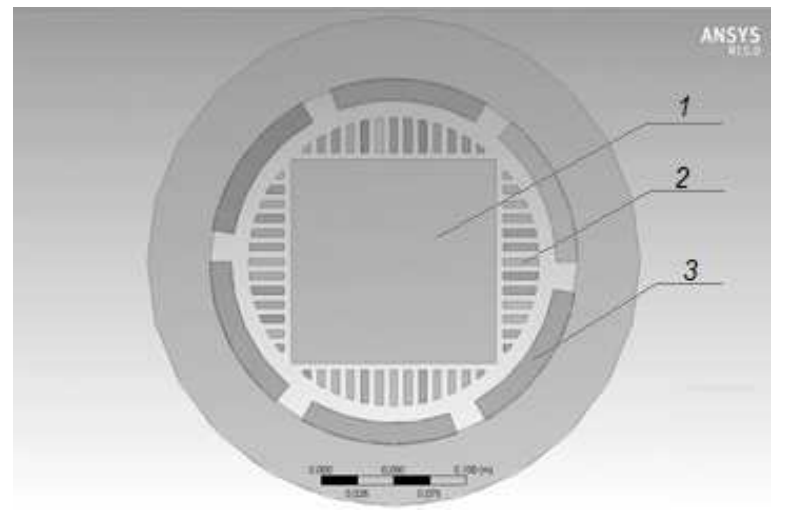

Fig. 9. Calculation scheme of the inductor-billet system with the use of the shipped magnetic field concentrators: 1-billet, 2-magnetic field concentrators in the form of a distributed magnetic circuit, 3-system of permanent magnets $[9,11]$

The maximum reduction is obtained with concentrators located along the side surfaces of the billet.

Figure 10 shows the dependence of the active power released in the billet on the number of plates of the allocated electromagnetic concentrator and the distance between them.

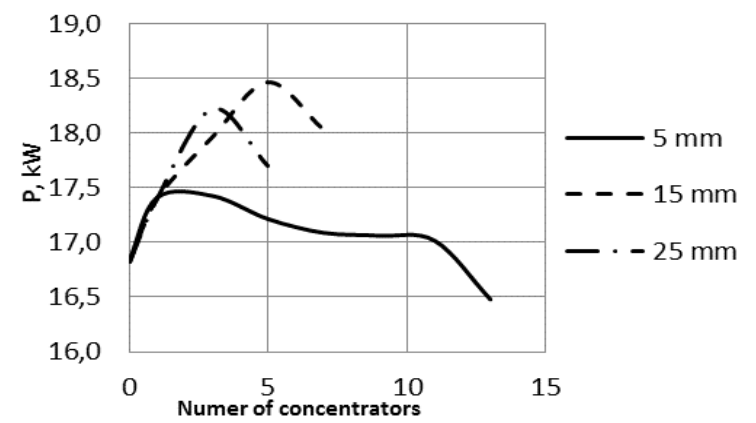

Fig. 10. Dependence of the integral active power released in the billet on the number of installed concentrator plates and the distance between them.

Figure 10 shows that the use of concentrators makes it possible to increase the input power by up to $9.8 \%$.

Figure 11 shows the dependence of the active power released in the billet on the filling factor and the percentage of overlapping the side of the billet with concentrators.

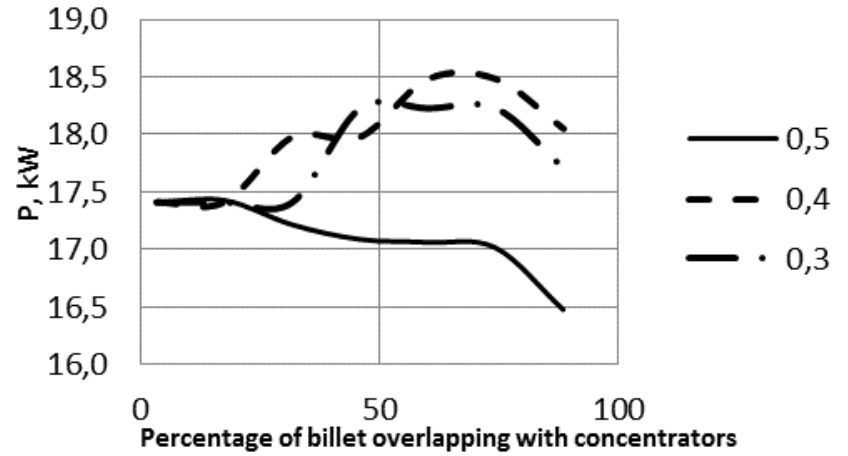

Fig. 11. Dependence of the integral active power released in the billet on the filling factor and the percentage of overlapping the side of the billet with concentrators.

When the side of the billet is covered by concentrators by an amount equal to $18 \%$ of the wide side of the billet, the filling factor does not have a significant effect on the input power, with an overlap of more than $74 \%$ leading to a sharp drop in the input capacity.

Figure 12 shows the temperature dependences of the number of concentrators located along the side surface of the billet and the distance between the concentrators.

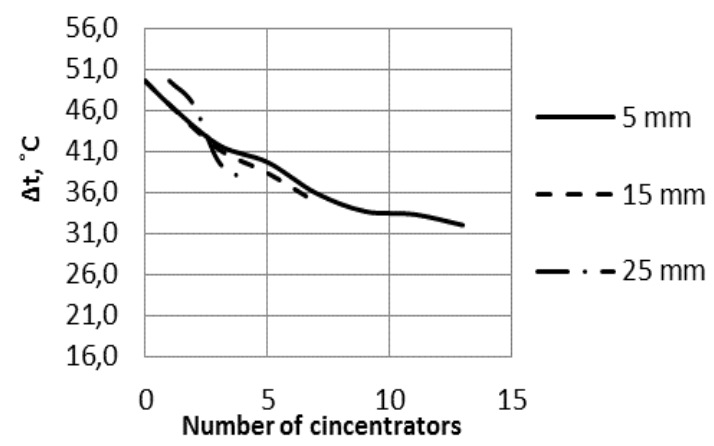

Fig. 12. Dependence of the temperature drop in the billet on the number of installed concentrators and the distance between them.

Figure 12 shows that increasing the distance between the installed concentrators leads to a decrease in the temperature drop in the billet.

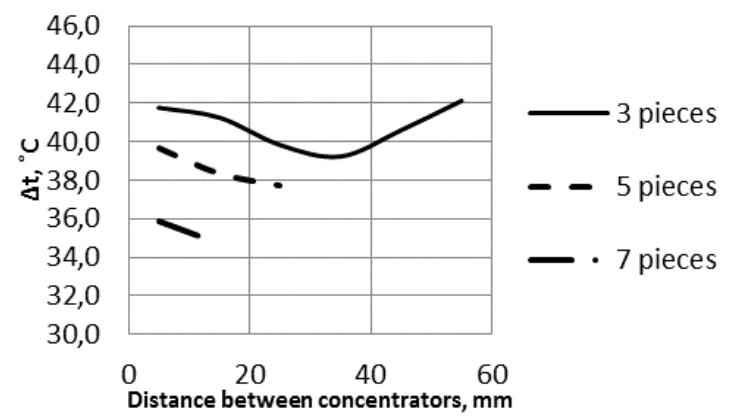

Fig. 13. Dependence of the temperature drop in the billet on the distance between the concentrators for several installed concentrators. 
An increase in the number of concentrators installed along the side surface of the billet leads to a decrease in the temperature drop in the billet. In this case, increasing the distance between concentrators of more than $35 \mathrm{~mm}$ for 3 concentrators leads to an increase in the temperature drop.

The installation on the side of the concentrators located close to the corners of the billet leads to a decrease in the temperature drop in the billet, as well as to a drop in the input power, which is due to the closure of the magnetic field through closely spaced concentrators. These concentrators in this case act as a screen for the magnetic field and reduce the overheating of the angle of the billet.

The most effective is the use of a configuration that provides maximum input of power into the billet with shielding of the corners of the billet to ensure that it has a minimum temperature difference.

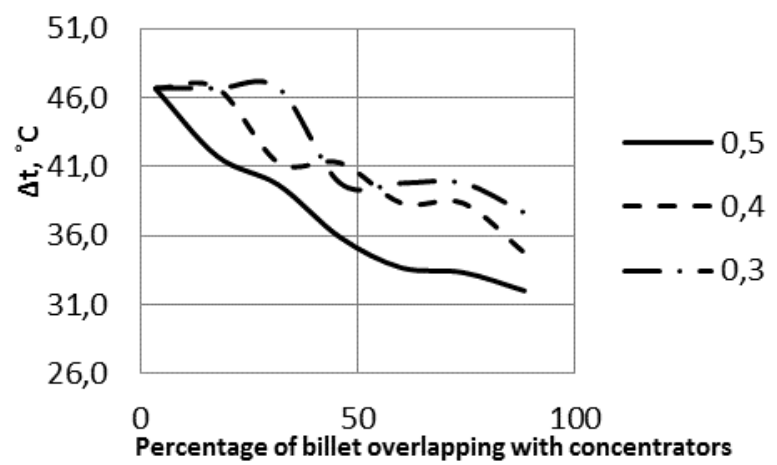

Fig. 14. Dependence of the temperature drop in the billet on the filling factor and the percentage of overlapping the side of the billet with concentrators.

\section{CONCLUSION}

As a result of numerical modeling of electromagnetic and thermal processes in the system "aluminum billet of rectangular cross section - permanent magnets rotating around it", the temperature field distribution in the billet is determined as a function of the rotation speed and the number of pole pairs of magnets in the absence and presence of magnetic field concentrators. The influence of several versions of the concentrators on the temperature field of the billet and the integrated power extracted in it are studied.

\section{References}

[1] A. Bojarevics, T. Beinerts, "Experiments on liquid metal flow induced by a rotating magnetic dipole", Magnetohydrodynamics, Vol. 46, No. 4, pp. 333-338, 2010.

[2] M. Bullo, M. Bertazzo, F. Dughiero, M. Forzan, M. Zerbetto, "Experimental results of a $55 \mathrm{kw}$ permananet magnet heater prototype", Proceedings of International conference on heating by electromagnetic sources, pp. 377-384, May 2013 [Induction, dielectric and microwaves, conduction \& electromagnetic processing, p. 671, 2013].

[3] P. Karban, F. Mach, I. Dolezel, "Higher-order finite element modeling of rotational induction heating of nonferromagnetic cylindrical billets", Proceedings of International conference on heating by electromagnetic sources, pp. 515-522, May 2010 [Induction, dielectric and microwaves, conduction \& electromagnetic processing, p. 647, 2010].

[4] F. Dughiero, M. Forzan, S. Lupi, F. Nicoletti, M. Zerbetto, "A new high efficiency technology for the induction heating of non magnetic billets", Proceedings of International conference on heating by electromagnetic sources, pp. 531-538, May 2010 [Induction, dielectric and microwaves, conduction \& electromagnetic processing, p. 647, 2010].

[5] F. Dughiero, M. Forzan, M. Zerbetto, "Permanent magnet heater for aluminum billets: Experimental results", Proceedings of 41st Annual Conference of the IEEE Industrial Electronics Society, pp. 5247-5252, May 2015 [41st Annual Conference of the IEEE Industrial Electronics Society, p. 5428, 2015].

[6] F. Dughiero, M. Forzan, S. Lupi, F. Nicoletti, M. Zerbetto, "A new high efficiency technology for the induction heating of non magnetic billets", The International Journal for Computation and Mathematics in Electrical and Electronic Engineering, 30 (5), pp. 1528-1538, 2011.

[7] I. Bucenieks, K. Kravalis, R. Krishbergs, "Pressure-flow rate characteristics of the pumps with permanent magnets", Magnetohydrodynamics, Vol. 47, No. 1, pp. 97-104, 2007.

[8] A. I. Aliferov, R. A. Bikeev, D. S. Vlasov, V. A. Promzelev, A. E. Morev, "Electromechanical and energetic characteristics of system of induction heating by permanent magnets", Proceedings of the 17 international conference of young specialists on micro/nanotechnologies and electron devices, P. 518-521, June - July 2016 [17 international conference of young specialists on micro/nanotechnologies and electron devices, p. 671, 2016].

[9] A. I. Aliferov, R. A. Bikeev, D. S. Vlasov, V. A. Promzelev, A. Morev, S. Lupi, "Energetic and thermal performance of induction heating system with permanent magnets", Proceedings of 11 International forum on strategic technology, Pt. 2, pp. 127-129 [11 International forum on strategic technology p. 625, 2016].

[10] F. Mach, P. Karban, I. Doležel, "Induction heating of cylindrical nonmagnetic ingots by rotation in static magnetic field generated by permanent magnets", Journal of Computational and Applied Mathematics, V. 236(18), pp. 4732-4744, 2012

[11] F. Mach, P. Kůs, P. Karban, I. Doležel, "Optimization of the system for induction heating of nonmagnetic cylindrical billets in rotating magnetic field produced by permanent magnets", Computing, V. 95(1), pp. 537552, 2013 